\title{
MEMÓRIA LITERÁRIA ARQUIVADA
}

Reinaldo Marques

UFMG

\begin{abstract}
Agosto de 1989. A Faculdade de Letras da Universidade Federal de Minas Gerais (UFMG) promove a Semana Henriqueta Lisboa. O evento assinala a doação, pela família, dos fundos documentais da poeta mineira à Universidade. Por meio dessa doação, um arquivo pessoal desloca-se do espaço privado para o espaço público, abrindo-se à pesquisa e ao movimento da suplementação de sentidos. O evento é precedido de repercussões no organograma e na burocracia da Faculdade: é criado o Centro de Estudos Literários (CEL), órgão interdepartamental responsável pela guarda e preservação do acervo recebido, por sua classificação e disponibilização para a pesquisa. ${ }^{1}$ Nessa oportunidade, num gesto de homenagem, pesquisadores e críticos dão seu testemunho sobre a escritora, sua trajetória intelectual, e se detêm no estudo da sua obra. Muitos dos trabalhos apresentados são publicados posteriormente no volume Presença de Henriqueta. ${ }^{2}$

Assim, um acontecimento datado e localizado - a referida Semana - e um documento bibliográfico - o volume publicado - compõem uma trama em que se configura o momento do arquivo. Momento marcado pela operação do arquivamento, por meio da qual o testemunho ingressa na escrita, convertendo-se em documento, em rastro do passado. ${ }^{3}$ No arquivamento, opera-se uma ruptura com o testemunho, normalmente oral e ouvido, pertencente à memória viva. Vivificada pela presença de um interlocutor preciso, a estrutura dialogal do testemunho cede lugar aos documentos depositados no arquivo, desvinculados de um destinatário específico, dos autores de seus testemunhos, mas submetido aos cuidados de seus arcontes, capaz de prestar-lhes socorro. Abrigados no silêncio do arquivo, desamparados e mudos, os documentos estão entretanto abertos a qualquer um que os saiba ler e interpretar. De sorte que o arquivo, em termos espaciais, constitui-se num lugar tanto físico quanto social, onde se guardam os rastros documentais do passado, de que se vale o historiador, por exemplo, para estabelecer as provas documentais necessárias à elaboração do conhecimento histórico.

Dessa operação de arquivamento, que supõe o espaço e o tempo como meios de inscrição, perceptíveis nos fenômenos da datação e da localização, emerge uma figura lastreada pela topografia acadêmica: o Acervo de Escritores Mineiros (AEM). Trata-se da emergência de um "lugar de memória", memória literária e cultural, como espaço a
\end{abstract}

\footnotetext{
${ }^{1}$ Hoje, após a mudança no organograma que eliminou a estrutura departamental, o CEL é um órgão complementar da Faculdade de Letras, aprovado pelo Conselho Universitário (Resolução nº. 19, de 22/11/2007). Está localizado no 3o andar da Biblioteca Central da UFMG, onde se abriga também o Acervo de Escritores Mineiros.

${ }^{2}$ CARVAlHO, SOUZA, MIRANDA (Org.). Presença de Henriqueta, 1992.

${ }^{3}$ Cf. RICCEUR. A memória, a história, o esquecimento, p. 176-180.
} 
ser vivido, construído e habitado. Vivido tanto imaginária quanto sensorialmente; construído seja pelo trabalho contínuo de gerações de pesquisadores, seja por inúmeras outras operações de arquivamento; habitado quer por corpos físicos, objetos, quer por desejos e sonhos.

Em sua emergência, o Acervo de Escritores Mineiros se dá, pois, como um gesto da memória inscrito no tempo e no espaço. O que significa, como forma de compreensão das possibilidades e limites desse mesmo gesto, apreender as condições de sua produção e reprodução no tempo e no espaço. Pensar o próprio arquivo, a construção da memória; examinar as forças em relação, suas inflexões e direções. O AEM registra a inserção da Faculdade de Letras da UFMG num movimento mais amplo, tanto local quanto global, relacionado aos cuidados com a memória, em geral, e com a memória literária e cultural, em particular. Restrinjo-me, neste ensaio, a ressaltar o contexto de seu surgimento, conectando-o com outras iniciativas similares e insinuando uma breve história dos arquivos literários entre nós, possíveis deslocamentos.

\section{ARQUIVOS LITERÁRIOS, NAÇÃO MODERNA E CAMPOS DISCIPLINARES}

Ao se pensar a configuração dos arquivos literários, não se pode deixar de situálos no contexto de uma história mais geral dos arquivos, especialmente no que concerne às relações do arquivo com a figura do Estado moderno, da administração pública. $O$ que implica um diálogo importante com a arquivística. Com o advento do Estado-nação, diversas instituições arquivísticas nacionais são criadas - o Arquivo, a Biblioteca, o Museu -, num processo que remonta à criação do Arquivo Nacional da França, em 1789. Se, antes da Revolução Francesa, havia uma descentralização na administração de arquivos, com essas novas formações arquivísticas verifica-se um tratamento mais centralizado e totalizante do arquivo. Percebe-se que, de um ponto de vista histórico, a constituição dos arquivos nacionais mostra-se correlata à formação dos Estados-nação, de sorte que a compreensão daqueles propicia um melhor entendimento destes.

Essa atenção aos arquivos, sobretudo aos conjuntos documentais produzidos pela administração pública, relaciona-se ao valor da informação arquivística e remete à idéia do Estado como "campo informacional", conforme ressalta José Maria Jardim:

A informação arquivística reflete e fornece elementos à construção de uma racionalidade estatal; os dispositivos de gestão dessa informação expressam um domínio do saber - o arquivístico - que resulta dessa mesma racionalidade; os arquivos - sejam como conjuntos documentais ou como agências do aparelho de Estado - constituem um mecanismo de legitimação do Estado e simultaneamente agências do poder simbólico. ${ }^{4}$

É no âmbito dessa racionalidade estatal e de seu apreço pela informação arquivística que a emergência e o cuidado com os arquivos literários devem ser situados. A desvinculação dos arquivos literários desse contexto, privilegiando-se apenas o paradigma estético, haverá de dificultar uma adequada compreensão dos mesmos enquanto instâncias de legitimação do Estado-nação e agência do poder simbólico.

${ }^{4}$ JARDIM apud FONSECA. Arquivologia e ciência da informação, p. 37. 
Importa conectar, pois, os arquivos literários com as memórias nacionais, enfocando o papel que tanto a literatura quanto os estudos sobre ela desempenham no mundo moderno como lugar de se imaginar a nação e de construção de identidades nacionais.

De acordo com a argumentação de Benedict Anderson, ao lado do jornal, o romance viabiliza a construção de uma imagem pedagógica da nação, de feição mítica e exemplar, baseada numa nova experiência da temporalidade - a de um "tempo homogêneo e vazio", em termos benjaminianos. Essa representação pedagógica da nação não deixa de ter um caráter patrimonialista, implicando uma manipulação de suas memórias e arquivos. Trata-se de estabelecer uma imagem e história oficiais da comunidade política imaginada, visível em fatos, heróis, datas, rituais, festas, eventos, símbolos, a que o tempo pedagógico procura emprestar um encadeamento necessário e rigoroso, uma indiscutível lógica causal. Seleção, recorte, descarte, classificação, locação, remissão essas diversas operações do arquivo são executadas com vistas à montagem de um arquivo nacional, cujos documentos, em seus usos pelo poder, transformam-se em monumentos.

Dentro dessa perspectiva, o arquivo expressa e reforça o tempo vazio e homogêneo da nação. Todavia, os elementos descartados, as memórias dos grupos subalternos, das minorias, que foram alijados do processo de enunciação do relato legitimador da nação, costumam se insinuar pelo vazio e pelo fragmento, como resíduo inclassificável, no arquivo das memórias oficiais da comunidade nacional. De tal maneira que o tempo pedagógico é atravessado e rasurado por outros relatos e temporalidades, de cunho contestador e transgressor da unidade nacional, evidenciando-se a heterogeneidade da nação moderna, seu hibridismo cultural. A cultura é vista então como instância de negociação de suas diferenças, compondo o que Bhabha designou como uma concepção performativa da nação. ${ }^{5}$

Heterogênea, a memória da nação não se restringe à cultura letrada, aos documentos escritos. Há que se levar em conta outras formas de inscrição da memória, próprias das tradições orais, ágrafas, em que o arquivo opera por meio das performances tanto verbais quanto corporais dos sujeitos. Cabe destacar aqui a dança, o canto, as teatralizações, as festas e rituais, presentes especialmente nas manifestações da cultura popular, compondo outras possibilidades de textos, de discursos para o sonho da nação. A configuração jurídica da comunidade nacional na modernidade, em termos do Estadonação, procurou circunscrevê-la a uma unidade territorial, fixando fronteiras geográficas, e a uma unidade linguística, com vistas à imposição de uma cultura unificada. Baseado no privilégio da escrita, da cultura letrada, esse procedimento significou, na prática, uma homogeneização cultural, em que se reduziram os aspectos heterogêneos, híbridos, de diferenciação da memória cultural, em prol da construção de uma imagem una e coesa da nação. Ao privilegiarem documentos escritos, a constituição dos arquivos nacionais reflete a predomínio da escrita, da cultura letrada, em detrimento das culturais orais, populares.

Como uma comunidade imaginada, seja enquanto relato que remonta o seu passado, seja enquanto sonho, projeção para o futuro, a nação moderna se realiza com base em intrincadas operações simbólicas e culturais, propiciadoras das identidades nacionais. Oscilando entre uma regressão aos tempos imemoriais e uma progressão para

${ }^{5}$ Cf. BHABHA. Disseminação: o tempo, a narrativa e as margens da nação moderna, p. 198-238. 
um futuro imprevisível, seu precário presente é atravessado permanentemente pelo embate entre forças antagônicas, simultaneamente de coesão e dispersão, de racionalidade e irracionalidade políticas, expressas em profundas divisões e diferenças internas - de classe, de gênero, de etnia - da sociedade nacional. Sua unidade só pode ser experimentada imaginariamente, pela atuação de poderosos mecanismos de poder cultural. Os arquivos são um desses mecanismos. Ao instituir seus arquivos e um saber correlato, o Estadonação procura ter o comando das operações simbólicas que viabilizam a formação de uma cultural nacional unificada e das identidades nacionais.

Ao lado dessa conexão dos arquivos com a figura da nação, outro aspecto contextual relevante a ser considerado relaciona-se à constituição moderna do campo disciplinar dos estudos literários. No âmbito da cultura letrada, que caracteriza o mundo moderno, especialmente no contexto de formação do Estado nacional, a literatura ocupa um lugar central. Expressão das elites nacionais cultas, ela é a grande mediadora nas relações entre a sociedade, a razão e o Estado. Produz imagens eloquentes que soldam as expressões culturais e políticas da nação; imagens em que diferentes sujeitos podem se reconhecer e se irmanar. Em sua força e prestígio simbólico, por meio de uma operação sinedóquica, a literatura, uma parte da cultura, é vista como se fosse a cultura. Em consonância com essa centralidade da literatura, desenvolvem-se um discurso e um saber sobre ela, capitaneado pela universidade. No interior da academia, nas Humanidades, conforma-se o campo moderno dos estudos literários com suas diversas disciplinas: Crítica, História, Teoria, Literaturas Vernáculas, Literatura Comparada. Constitui-se um saber literário, aquele produzido pelo discurso da universidade sobre a literatura, e que tem no Estado-nação o seu referente social primário.

Importa aqui a articulação entre o Estado moderno e o aparecimento da universidade enquanto "centro nacional estatal hegemônico, de controle e liderança da pesquisa e da docência". ${ }^{6}$ Trata-se da universidade moderna como sistema totalizante, que visa assimilar e acumular todos os saberes, submetendo-os à primazia do método, reduzindo sua diversidade à unidade. Como tal, o Estado nacional encontra na universidade moderna um poderoso aliado, que tem como finalidade produzir um conhecimento científico, "verdadeiro", sobre a nação, desvelando seu princípio constitutivo, sua especificidade. Conforme mostrou Michel Foucault, por meio dessa universidade que surge em fins do século 18 e início do século 19, e que coincide, não por acaso, com o mesmo momento de nascimento da nação moderna, realiza-se um grande disciplinamento dos saberes. ${ }^{7}$ Disciplinamento marcado pela seleção, normalização, distribuição, hierarquização e homogeneização dos saberes. Através dele, saberes menores são esvaziados e integrados de modo subalterno aos arquivos da universidade, ao passo que outros, os saberes selvagens produzidos fora dos muros acadêmicos, são descartados e excluídos como não-saberes.

Relacionados ao papel privilegiado da cultura letrada e da literatura, os saberes disciplinares e disciplinados dos estudos literários são integrados aos arquivos da

\footnotetext{
${ }^{6}$ THAYER. A crise não moderna da universidade moderna, p.17.

${ }^{7}$ Cf. FOUCAULT. Em defesa da sociedade - curso no Collège de France (1975-1976), p. 217-219.
} 
universidade moderna. Cada disciplina procura definir seu método e objeto, constituindo também seu arquivo específico. Cabe à História da Literatura, por exemplo, elaborar as histórias literárias nacionais, sob o pressuposto de que nas obras literárias se desvela o espírito nacional, identificado muitas vezes à alma do povo. Ao cunhar o conceito de "literatura nacional" na segunda metade do século 18, Johann Gottfried Herder concebia-o "como a expressão mais completa da evolução espiritual de uma nação". 8 Entre nós, uma obra clássica desse campo disciplinar, a Formação da literatura brasileira (momentos decisivos), de Antonio Candido, é tributária da idéia de "certa encarnação literária do espírito nacional". ${ }^{9}$ Compete a tais histórias evidenciar autores e obras representativos da alma nacional, de tal modo que construir uma nação implica reduplicála como uma nação literária. ${ }^{10}$ Integram, pois, os arquivos da História da Literatura documentos relativos a essas obras e seus autores, possibilitando a instituição de um cânone literário nacional. Processo que significa a exclusão e o esquecimento daquelas obras e autores tidos como não-representativos, relegados, quando muito, ao pé-de-página.

Para essa tarefa haverá de colaborar, de um lado, a Crítica Literária, indicando os valores "autenticamente" literários, estabelecendo um paradigma estético-historicista de apreciação da literatura, apto a formar o gosto dos leitores da comunidade nacional; de outro, a Literatura Comparada, ao promover a aproximação entre obras características de cada literatura nacional, fixando semelhanças e diferenças entre elas, que terminam por realçar as especificidades de cada nação. Já a Teoria Literária, ou uma Ciência da Literatura, em termos do século 19, permite a formação de um arquivo teórico, com suas ferramentas conceituais, capaz de subsidiar as operações analíticas e descritivas das demais disciplinas do campo dos estudos literários.

Nesse contexto, pode-se dizer que a criação das Academias Nacionais de Letras e das Bibliotecas Nacionais articula-se, complementando-o, com esse processo de disciplinamento dos saberes estabelecido pela universidade moderna. As Bibliotecas, ao possibilitarem a acumulação do saber letrado produzido, especialmente sobre a nação; as Academias, ao contribuírem para a consagração dos autores representativos, para a normalização de sua conduta, que deve se tornar profissional frente à mediação do mercado. Tudo isso contribui para a elaboração e consolidação de um paradigma históricoestético de legitimação das narrativas nacionais.

A título de ilustração, tome-se o caso de nossa Academia Brasileira de Letras (ABL). Brito Broca considera sua fundação, em 1896, um dos fatores responsáveis pela decadência de uma geração boêmia de escritores por volta de 1900. O outro consiste na onda modernizadora da época do prefeito Pereira Passos - um barão Haussmann dos trópicos -, que transforma a paisagem urbana do Rio de Janeiro, com a criação de grandes avenidas, como a Av. Central, incompatíveis com a vida boêmia. À influência da ABL o crítico debita o aburguesamento de nossos escritores na primeira década do século 20. Presidida por Machado de Assis e dotada de uma dignidade oficial avessa ao

\footnotetext{
${ }^{8}$ Cf. CARPEAUX. História da literatura ocidental, v. I, p.13.

${ }^{9}$ Cf. CANDIDO. Formação da literatura brasileira (momentos decisivos), v. 1, p.26.

${ }^{10}$ Conferir, a propósito, MIRANDA. Nações literárias, p. 31-38.
} 
estilo boêmio, para ingressar nela o escritor carece de ter compostura, boas maneiras. Pré-requisito indispensável, conforme demonstra a oposição de Machado à entrada de Emilio de Menezes, poeta boêmio e membro da concorrente Academia Livre de Letras, adepto de um bom copo de cerveja. ${ }^{11} \mathrm{O}$ episódio reflete a inadequação de um estilo boêmio de vida às regras utilitárias e práticas da vida profissional, marcadas pela mediação do mercado. E evidencia o papel normalizador exercido pela ABL, num momento de profissionalização do escritor, tornando-se parte da engrenagem social. Regida por um ethos profissional, a Academia contrapõe-se à visão romântica do poeta, que o liga à vida boêmia. Todavia, entrar na Academia é ingressar no arquivo, na memória, e para tanto importa se transformar num escritor normalizado. Razão por que alguns intelectuais boêmios da época, como o próprio Emilio de Menezes, Dermeval da Fonseca, B. Lopes e Lima Barreto, não deixarão de bater às portas da ABL.

A propósito de uma história dos arquivos literários no Brasil, não se pode deixar de apontar o papel pioneiro do arquivo da Academia Brasileira de Letras. ${ }^{12}$ Já nas sessões plenárias iniciais, em 1897, existem manifestações de acadêmicos, registradas em atas, preocupados com a recolha de documentos. Todavia, é apenas na Ata de 16/12/1943, no contexto do Estado nacional popular da era Vargas, que se encontra uma referência explícita à estruturação de um arquivo na $\mathrm{ABL}$, relacionada à discussão do Projeto de Reforma do Regimento Interno da Casa. Na sessão de 23/12/1943, Múcio Leão assume a presidência, ficando responsável pela primeira fase de organização do Arquivo; na sessão de 23/12/1948, ele é reeleito Diretor do Arquivo, cargo que ocupou até sua morte, em 12/08/1969. Com a gestão de Nélida Piñon, a partir de 1997, desenvolve-se um projeto de revitalização do Arquivo da Academia Brasileira de Letras (AABL). ${ }^{13}$

À luz então de modernos princípios de arquivística, o AABL distingue duas linhas de acervo arquivístico na sua organização: o Arquivo dos Acadêmicos, contendo documentos privados e pessoais dos escritores, e o Arquivo Institucional, abrigando documentos administrativos e funcionais produzidos, recebidos e acumulados em razão das atividades-meio e atividades-fins da ABL. O Arquivo dos Acadêmicos é composto de documentos textuais, originais manuscritos, datilografados e impressos em suporte papel, recortes de jornais e revistas, películas cinematográficas, registros magnéticos (fitas de áudio e de vídeo, CD-ROMs e disquetes), fotografias, diplomas, cartazes, cartões de visitas. Constituem o conteúdo de tais documentos depoimentos pessoais e profissionais, originais literários, discursos, correspondências, entrevistas, atuações culturais etc. ${ }^{14}$

\footnotetext{
${ }^{11}$ Cf. especialmente o capítulo 2 de BROCA. A vida literária no Brasil -1900.

${ }^{12}$ Caberia ver em que medida entram nesse pioneirismo a Biblioteca Nacional, que dispõe de uma Seção de Manuscritos Literários, e até mesmo o Instituto Histórico e Geográfico Brasileiro, criado no Segundo Império.

${ }^{13}$ Cf. Arquivo dos Acadêmicos: Guia geral, p. 15-20.

${ }^{14}$ Ibidem, p. 19.
} 


\section{ARQUIVOS LITERÁRIOS BRASILEIROS: HISTÓRIAS LOCAIS}

Em termos mais locais e contemporâneos, no que concerne à formação dos arquivos literários no Brasil, tem sido proeminente o papel das universidades, tanto públicas quanto privadas. Com efeito, no interior das nossas instituições universitárias foram criados diversos centros de documentação e de memória especialmente no âmbito das ciências humanas, como forma de subsidiar a pesquisa em várias áreas, tais como: a sociologia, a história, a antropologia, a literatura, as artes. Criação motivada seja pela carência de investimentos por parte de instâncias do poder público na preservação de seu patrimônio arquivístico, seja pelas dificuldades de acesso às fontes de pesquisa. Tais centros empenham-se na reunião, organização e preservação de arquivos e coleções, de conjuntos documentais diversificados, contribuindo para a salvaguarda do nosso patrimônio quer arquivístico e bibliográfico, quer museológico. Com isso, à tarefa primeira de geração de conhecimento e sua disseminação, as universidades agregaram a tarefa de organização e preservação das fontes primárias de pesquisa, bem como de sua disponibilização para a consulta por parte da comunidade acadêmica e do público em geral.

Mas a constituição e o cuidado com acervos literários são tardios entre nós. Como tardio não deixa de ser o interesse pelo estudo das correspondências dos escritores, em razão seja da organização retardatária desses mesmos arquivos, seja da exigência de um certo um lapso de tempo para acessar os documentos, após a morte do escritor. Basta ter presente alguns dados relativos à criação de alguns de nossos principais centros de documentação literária. O primeiro deles é o Instituto de Estudos Brasileiros (IEB) da Universidade de São Paulo (USP), que foi criado em 1962, por iniciativa de Sérgio Buarque de Holanda. Abriga hoje arquivos de alguns de nossos mais importantes escritores, tais como os de Mário de Andrade, Guimarães Rosa, Graciliano Ramos.

Em seu estudo sobre as origens e significados do IEB, João Ricardo de Castro Caldeira ressalta tratar-se de "organismo multidisciplinar e multitemático especializado nos estudos sobre Brasil". ${ }^{15}$ Diversamente de outras instituições, criadas naquele contexto histórico com base em paradigmas internacionais, o IEB tem como objeto de estudo o Brasil, segundo uma perspectiva local, regional. Para o que se constitui num ponto de articulação de diferentes disciplinas do campo das Humanidades: antropologia, história, música, arquitetura, literatura, artes. Seu referente é, pois, a nação - o Brasil -, "tomado segundo perspectivas múltiplas e variadas, e abordado conforme suas especificidades" ${ }^{16}$ Todavia, conforme anota o pesquisador, o modelo do IEB é o do area studies center, formulado nas academias do Norte no contexto de uma geopolítica do conhecimento marcada pela Guerra Fria, pela polarização entre o mundo capitalista e o mundo comunista. Trata-se de "órgão universitário especializado no estudo de uma ou mais regiões - países, continentes, subregiões etc., fundamentado na multidisciplinaridade", contendo acervos documentais variados sobre as regiões estudadas e contando com a colaboração de

${ }^{15}$ Cf. CALDEIRA. IEB: origens e significados - uma análise do Instituto de Estudos Brasileiros da Universidade de São Paulo, p. 21; grifos do autor.

${ }^{16}$ Ibidem, p. 22; grifos do autor. 
pesquisadores de várias disciplinas. ${ }^{17}$ Como unidade dinâmica e complexa, um area studies center promove pesquisas, cursos, exposições e edições de livros e periódicos especializados.

Em relação ao contexto de emergência do IEB, importa ainda assinalar a inserção da USP numa onda modernizadora que se instala entre o início da década de 1950 e o golpe militar de 1964. Onda insuflada pelo clima de otimismo, pela ideologia desenvolvimentista, amparada no crescimento econômico, no investimento do Estado em infra-estrutura para viabilizar a expansão industrial, em avanços democráticos na política. Surfando nessa onda, a Universidade procura se transformar num "laboratório de estudos" sobre o Brasil, para o que contribui de modo significativo a montagem do IEB. No que concerne à educação e à ciência, são dessa época a criação da CAPES e do CNPq, ambos de 1951, e da FAPESP, de 1960, como importantes agências de regulação e de financiamento do ensino e da pesquisa nas universidades brasileiras.

O que temos então é um momento de redescoberta do Brasil, que se manifesta na cultura em distintos e contraditórios projetos para se ler e explicar o país - cinema novo, bossa nova, poesia concreta, Teatro de Arena, bienais de arte, construção de Brasília, centros populares de cultura. Alguns de cunho eufórico; outros, de caráter disfórico. Procurando participar do processo de mudanças em andamento, observa Caldeira que na USP de então se confrontam duas maneiras de abordagem da realidade nacional. De um lado, uma corrente externalista, que submete o estudo do Brasil ao movimento do capitalismo internacional, incorporando-se o marxismo como vertente crítica desse movimento; de outro, a corrente internalista, empenhada no estudo dos mais diversos assuntos, com predomínio das questões culturais, segundo um pluralismo metodológico. ${ }^{18}$ Nesse embate, prevaleceu a forma externalista, dos estudos econômicos e sociológicos, sob os auspícios da Sociologia, das análises de Celso Furtado e do CEPAL.

Para uma melhor compreensão do contexto de formação dos arquivos literários no Brasil, o surgimento do IEB nos impõe alguns elementos para reflexão. De um lado, sua criação procura atender demandas do Estado-nação num contexto periférico, com vistas a articular identidades e especificidades nacionais à luz daquele movimento do capitalismo internacional. Nesse sentido, suspeito que suas pesquisas no campo da antropologia, das artes, da cultura não deixam de contribuir para revelar a complexidade e ambivalência das identidades nacionais, oferecendo certo contraponto aos modelos econômicos e sociológicos de interpretação do Brasil. Por outro lado, se seu objeto de investigação é uma realidade interna, local e regional, mostra-se dissonante o fato de que tenha se servido de um modelo externo - o do area studies center -, criado como resposta epistemológica para questões geopolíticas das nações do Primeiro Mundo, questões bem diversas daquelas do Terceiro Mundo, valendo-se de categorias explicativas da época. Com o triunfo da globalização, promovendo a expansão planetária do capitalismo, com a falência da União Soviética e o fim da Guerra Fria, na década de 1980, entram em crise o paradigma do Estado-nação e, consequentemente, os area studies center, acarretando uma nova configuração mundial da produção do conhecimento. Novos

${ }^{17}$ Cf. CALDEIRA. IEB: origens e significados - uma análise do Instituto de Estudos Brasileiros da Universidade de São Paulo, p. 23.

18 Ibidem, p. 39. 
saberes, novas disciplinas, metodologias e modelos são desenhados, como os dos Estudos Culturais, refletindo-se no espaço acadêmico. É sobretudo nesse contexto que surgirão vários outros arquivos literários no Brasil, nas universidades e fora delas.

Nos anos de 1970 são implementados mais dois centros de documentação literária. O Arquivo-Museu de Literatura Brasileira (AMLB) da Fundação Casa de Rui Barbosa (FCRB), no Rio de Janeiro, foi instalado em 28/12/1972. Segundo Eliane Vasconcellos, ele materializa uma fantasia do poeta e cronista Carlos Drummond de Andrade, que, em sua coluna do Jornal do Brasil de 11/07/1972, lamentava a falta de um museu de literatura, como defesa contra as perdas da nossa memória literária: "Mas falta o órgão especializado, o museu vivo que preserve a tradição escrita brasileira, constante não só de papéis como de objetos relacionados com a criação e a vida dos escritores. É incalculável o que se perdeu, o que se perde por falta de tal órgão." ${ }^{19}$ Conferindo ao museu e à memória um caráter compensatório, a fantasia de Drummond ganha corpo nos encontros de sábado na casa de Plínio Doyle, de que participa o presidente da FCRB à época, Américo Lacombe. Apelos do próprio Drummond, em crônicas na imprensa, e de Plínio Doyle, para que doações de documentos, peças e acervos literários, fossem feitas ao novo museu surtem efeito e logo o AMLB já possui um acervo de 500 peças. Com o passar do tempo, o crescimento desse acervo será estimulado pelas exposições, divulgações de pesquisas em artigos, periódicos e livros. Em 1999 já contava com 69 arquivos privados de escritores brasileiros e 26 coleções de documentos valiosos, pertencentes a Manuel Bandeira, Carlos Drummond de Andrade, Pedro Nava, Lúcio Cardoso, Cornélio Pena, Vinícius de Morais, Clarice Lispector, entre outros. ${ }^{20}$ Hoje o AMLB abriga o maior conjunto de documentos, coleções e acervos literários do país, sofrendo com o problema da falta de espaço para um tratamento mais adequado dos seus materiais.

A partir de 1978, com a doação da biblioteca do poeta juizforano Murilo Mendes, é implementado o Centro de Estudos Murilo Mendes (CEMM) da Universidade Federal de Juiz de Fora (UFJF). Dada a relevância da biblioteca do escritor, com cerca de 2.800 volumes das mais diversas áreas do saber e das artes, para este Centro confluem também pesquisadores de distintos campos de estudo - filosofia, literatura, artes plásticas etc. , dotando-o de uma perspectiva também transdisciplinar. Mais tarde, em 1993, contando com apoio de órgãos governamentais e da Prefeitura da cidade, novas gestões da UFJF junto à viúva do escritor, Maria da Saudade Cortesão Mendes, resultaram na doação da valiosa pinacoteca do escritor e do restante do acervo. ${ }^{21}$ Para se dar uma maior visibilidade à coleção de arte moderna do poeta, conferiu-se um indispensável tratamento museográfico ao acervo de artes plásticas muriliano, com a realização de exposições.

Já na década de 1980 assiste-se à constituição de mais quatro relevantes acervos literários. Instalado no Centro de Memória Literária da Faculdade de Letras da Pontifícia Universidade Católica do Rio Grande do Sul (PUC-RS), o Acervo de Escritores Sulinos (AES) foi criado em 1982, a partir da organização dos documentos legados por Érico Veríssimo. Aos arquivos do autor de $\mathrm{O}$ tempo e o vento se somaram os de outros escritores importantes

\footnotetext{
${ }^{19}$ ANDRADE, Carlos Drummond apud VASCONCELLOS. Preservação da memória literária, p. 41.

${ }^{20}$ Cf. VASCONCELLOS. Preservação da memória literária. p.46-48.

${ }^{21}$ Cf. BARBOSA, RODRIGUES. Centro de Estudos Murilo Mendes: registros, p. 178-189.
} 
do Sul nos anos seguintes, tais como os de Dyonélio Machado, Mário Quintana, Zeferino Brasil e Josué Guimarães. No AES, são desenvolvidos projetos de pesquisa sobre fontes da literatura brasileira, revitalizando-se o campo da história da literatura, e foram realizados, nos anos de 1990, os primeiros encontros de pesquisadores de acervos literários, para intercâmbio de experiências de organização, conservação e divulgação de arquivos de escritores. ${ }^{22}$

Em 1984, no Instituto de Estudos da Linguagem da UNICAMP, surge o Centro de Documentação Alexandre Eulálio, inicialmente como espaço apropriado para a organização e conservação de materiais recolhidos pelas pesquisas dos docentes. Pesquisas que contribuem para captar os acervos de Monteiro Lobato, Oswald de Andrade, Bernardo Elis, Hilda Hilst, entre outros. Já em 1986, no Centro Histórico de Salvador e Largo do Pelourinho, foi instalada a Fundação Casa de Jorge Amado (FCJA) ${ }^{23}$ Fundação privada, abriga um conjunto de 200 mil documentos, distribuídos em três acervos: "Acervo Jorge Amado" - com a documentação pessoal do escritor baiano, contendo registros da gênese, publicação, circulação e leituras de sua obra; o "Acervo Zélia Gattai", em que se destaca importante acervo fotográfico sobre Jorge Amado e sua mulher, além de livros publicados, traduções e testemunhos da recepção crítica; e o acervo sobre a própria Casa de Jorge Amado, constituído por registros de sua criação, documentos sobre as atividades e promoções da instituição. Abrigando o arquivo pessoal de Jorge Amado, como amplificação dos efeitos de sua obra, a Casa vincula-se sobretudo a uma memória local, constituindo-se num arquivo da baianidade.

Por fim, como se viu, em 1989 dá-se a criação do Acervo de Escritores Mineiros, junto ao Centro de Estudos Literários da Faculdade de Letras da UFMG. Abriga hoje os acervos bibliográficos e documentais de escritores e intelectuais mineiros relevantes no panorama cultural do país: Henriqueta Lisboa (1901-1985), Murilo Rubião (1916-1991), Oswaldo França Júnior (1936-1989), Abgar Renault (1901-1995), Cyro dos Anjos (1906-1994), Octávio Dias Leite (1914-1970), Wander Piroli (1931-2006), José Maria Cançado (1952-2006) e Fernando Sabino (1923-2004). A esses acervos somam-se ainda algumas coleções especiais, constituídas por cartas de escritores, livros, revistas e fotografias, como as de Alexandre Eulálio (1932-1988), Aníbal Machado (1894-1964), Ana Hatherly (1929), Valmiki Villela Guimarães (1934), José Oswaldo Araújo (1887-1975) e Genevieve Naylor (1915-1989).

Depois de enfrentar dificuldades quanto ao espaço para sua localização, o AEM dispõe atualmente de um ambiente adequado para guarda de seus acervos, situado no terceiro andar da Biblioteca Universitária da UFMG, no campus Pampulha. Inaugurado em dezembro de 2003, esse espaço resultou de uma parceria bem sucedida de diferentes órgãos e instituições públicas. ${ }^{24}$ Ademais, sua concretização vincula-se a uma preocupação mais geral da Universidade com a organização, preservação e conservação dos seus acervos culturais e artísticos, documentais e arquitetônicos.

\footnotetext{
${ }^{22}$ Cf. BORDINI. Acervos Sulinos: a fonte documental e o conhecimento literário, p. 129-139.

${ }^{23}$ Cf. CUNHA. A "Casa de Jorge Amado", p. 122.

${ }^{24}$ O Ministério da Ciência e Tecnologia concedeu a verba para construção da obra, através do FUNDO CT INFRA/FINEP, e tem financiado o Projeto de Pesquisa Acervo de Escritores Mineiros, com o apoio do CNPq, desde 1991. Na UFMG, foram imprescindíveis os apoios da Biblioteca Universitária, cedendo o espaço, da Faculdade de Letras, da Reitoria e da FUNDEP.
} 
Do ponto de vista arquitetônico, o espaço foi concebido numa perspectiva cenográfica e museográfica, comportando três planos. No primeiro, são simulados os ambientes de trabalho dos escritores, com estantes de livros, mesa, máquina de escrever, objetos pessoais. Devidamente reconstituídos a partir de pesquisa junto aos familiares, nesses ambientes encontram-se também documentos raros expostos em vitrines, a exemplo de primeiras edições autografadas, cartas de escritores, fotografias. A individualidade de cada recinto, procurando realçar a personalidade do escritor, é garantida por meio de iluminação com jogo de cores, perfis e textos ilustrativos. No segundo, encontram-se as galerias com exposições de obras de artes plásticas: pinturas, esculturas, fotos, pôsteres. Por fim, no terceiro plano, com acesso restrito, estão abrigados os acervos bibliográficos e os arquivos documentais de cada escritor. $O$ espaço contém ainda reserva técnica, sala de reunião e área de trabalho para pesquisadores e estagiários, normalmente estudantes bolsistas de Iniciação Científica. A proteção de todo esse valioso acervo é feita por monitoramento eletrônico de câmeras e sistema de alarme.

Dentro dessa concepção, foi contemplada a natureza heterogênea dos materiais que compõem os acervos literários, uma mistura de elementos próprios de bibliotecas, arquivos e museus - livros, periódicos, correspondências, recortes de jornais, pinturas, esculturas, fotografias, mesas, estantes, máquinas de escrever, objetos pessoais, coleções. Com isso, o espaço do Acervo de Escritores Mineiros da UFMG configura-se como um espaço móvel e permanente de exposição, conseguindo focar, no plano geral, as singularidades de cada material. Abre aos visitantes e pesquisadores a possibilidade de cada um, com seus recortes e enquadramentos, constituir a sua própria trilha, o seu próprio texto, ao percorrer os diversos níveis espaciais. Dotado de múltiplas perspectivas e entradas, desvela o texto da memória literária e cultural em sua complexidade de sentidos, visível quer na seleção quer na combinação, justaposição ou sobreposição de objetos heteróclitos.

Ao dar ao texto da memória cultural e literária do país um tal tratamento, a Universidade procura, por um lado, dar continuidade a um projeto dos próprios escritores mineiros, que sempre cultivaram os gêneros memorialísticos e cuidaram de montar seus arquivos pessoais ao longo da vida. No trabalho com seus acervos, logo o pesquisador depara com uma "compulsão arquivística", que neles é um traço saliente. ${ }^{25}$ Até mesmo atávico, fruto de forte inclinação memorialística e autobiográfica, emblematizada por aquelas arcas e baús muito comuns nas fazendas coloniais mineiras, funcionando como arquivos de uma Minas arcaica e ancestral. Com efeito, percebe-se nos nossos escritores um empenho zeloso para guardar papéis e documentos, armazenar recortes de jornais, arquivar e ordenar originais manuscritos ou datiloscritos, correspondências (cartas, bilhetes, cartões postais, telegramas), acumular fotografias, montar bibliotecas, preservar objetos pessoais. E também a prática do colecionar: revistas, suplementos literários, obras de artes, obras de artesanato. Disso dão testemunho, por exemplo, os álbuns fotográficos de Abgar Renault, registrando sobretudo a trajetória do homem público, ocupado e preocupado com os rumos da educação no país; a correspondência de Henriqueta Lisboa, evidenciando uma rede de relações literárias e afinidades intelectuais e afetivas; a coleção do

${ }^{25}$ Cf. MARQUES. O arquivamento do escritor, p.141-156. 
Suplemento Literário de Murilo Rubião, sua biblioteca pessoal. Este é talvez o escritor mais atacado pela prática arquivística, marcada pelo rigor na ordenação e classificação dos materiais, pelo cuidado com sua conservação, como indica seu hábito de colocar capa dura em todos os livros.

As práticas de arquivamento dos escritores, menos que fruto de uma injunção meramente social, resultam de uma rede de relações literárias e afinidades intelectuais na qual se inscrevem. Revelam um cuidado com a memória do escritor, com sua formação intelectual, capaz de possibilitar a construção de sua imagem enquanto autor significativo. Ao arquivar correspondências de amigos e críticos, artigos em jornais contendo críticas sobre seus livros, o escritor preserva uma fonte inesgotável de paratextos, que ajudam a entender a produção e recepção de sua obra.

Com isso, a criação dos centros de documentação e memória, a constituição e preservação de arquivos nas nossas instituições universitárias, a par de tornar a informação mais próxima do pesquisador, contribuem também para o cuidado e a preocupação com a documentação local, para a proteção da memória regional. Promovendo a indissociabilidade entre acervo e pesquisa, esses arquivos e centros de documentação constituem instâncias vitais para a construção do conhecimento e ampliação das possibilidades de cidadania, na medida em que transformam a informação especializada em conhecimento público, tornando-a acessível ao maior número de pessoas.

A instalação desses centros dedicados a organizar e preservar nossos arquivos literários situa-se, como se vê, basicamente no contexto dos anos 1970 e 1980, marcado por uma intensa preocupação com os lugares da memória e, ao mesmo tempo, por forte pressão de mecanismos de amnésia social e histórica, responsável pela fetichização do passado, convertido em mercadoria no Disney World. Vivemos, paradoxalmente, uma crise da memória. Crise alimentada pelas transformações de nossas concepções do passado e das relações com ele estabelecidas. Antes transparente, mantendo vínculos naturais com o presente, segundo uma concepção linear e evolutiva do tempo histórico, a natureza do passado tornou-se opaca, fonte de incertezas e inquietações. ${ }^{26}$

\section{A PESQUISA EM ARQUIVOS LITERÁRIOS: DESLOCAMENTOS}

À guisa de conclusão, gostaria de assinalar sumariamente possíveis impactos das pesquisas em arquivos literários no campo dos estudos da literatura, promovendo alguns deslocamentos especialmente no âmbito da literatura comparada. Essas pesquisas certamente ampliarão o corpus de materiais postos em comparação, potencializando uma tendência já marcante do comparatismo literário. Desfazem o privilégio do texto acabado, da obra, em sua fatura linguística, para colocar em cena os manuscritos, as correspondências, as fotografias, os recortes, as coleções. O tratamento museográfico e cenográfico dos acervos literários, ao realçar as coleções de obras de arte dos escritores (pinturas, esculturas, desenhos etc.), estimula o diálogo interartístico, possibilitando aproximar e contrastar

\footnotetext{
${ }^{26}$ Cf. MENESES. A crise da memória, história e documento: reflexões para um tempo de transformações, p. 11-29.
} 
as artes. No acervo de Henriqueta Lisboa, por exemplo, há uma coleção de quadros de Petrônio Bax, pintor mineiro, que lhe inspirou alguns poemas. A ele ela dedicou um poema-homenagem intitulado "Roteiro de Petrônio Bax". Já no acervo de Oswaldo França Júnior, há uma coleção de peças de artesanato do Caribe, formada por miniaturas de casais em atitudes eróticas; de forma deslocada, pode-se pensar tal coleção como a presença das tradições orais no espaço da cultura letrada.

Outra ressonância do trabalho com arquivos literários consiste em incrementar o trânsito transdisciplinar já marcante nos estudos comparados. Com efeito, tendo em vista a heterogeneidade de materiais que constituem os arquivos literários, um tratamento mais adequado dos acervos de escritores demanda a articulação de diferentes saberes, disciplinas - arquivística, museologia, biblioteconomia, informática, arquitetura. Além disso, uma diversidade de discursos é agenciada pelos arquivos literários: teórico, histórico, crítico, ficcional, memorialístico, biográfico, autobiográfico, epistolar, etc. Assim, há uma gama variada de textos a serem comparados, com repercussões metodológicas. No caso do discurso crítico, por exemplo, nota-se o diálogo tenso entre diferentes orientações críticas, marcadas por distintos pressupostos: a crítica textual, a crítica genética e a crítica biográfica. A tendência que se observa então é a de uma abertura cada vez maior do campo comparatista literário, como forma de contemplar os diversos objetos dos arquivos literários.

Um outro deslocamento a ser apontado consiste numa nova configuração do perfil do pesquisador, em geral, e do comparatista, em particular. Entendo que, para lidar de forma crítica com os arquivos literários, o pesquisador e comparatista deve atuar como um arquivista anarquista, lendo o arquivo a contrapelo. Nesse sentido, o pesquisador busca desconstruir a ordem estabelecida no arquivo, contestando a intencionalidade que o erigiu. Como um sujeito desconfiado da solenidade das origens, dos protocolos da lei, da retórica do princípio, busca instaurar uma anomia no arquivo, estimuladora de novas leituras de seus materiais. Se o arquivista se pauta pelo respeito à proveniência do arquivo, à ordem original, o pesquisador, como arquivista anarquista, busca subverter a ordem original, lendo os documentos de outra forma, dentro de outras (des)ordens possíveis. Só assim ele logrará deslocar nossa história cultural, formulando outras maneiras de a ler e interpretar.

Nessa direção, entendo que o trabalho em arquivos literários, fomentando a pesquisa com fontes primárias, por um lado contribui para revitalizar as disciplinas dos estudos literários, a exemplo da história da literatura, ${ }^{27}$ mas, por outro, no longo prazo, haverá de aprofundar a crise do paradigma disciplinar moderno, ao incrementar o trânsito entre os saberes, as tópicas transdisciplinares, desvelando um cenário pós-disciplinar. $\mathrm{Na}$ medida em que problematizam categorias canônicas dos estudos literários, tais como: texto, obra, autor, valor estético universal, os saberes do arquivo tornam mais rarefeitos os fundamentos das disciplinas acadêmicas. Como remédio e veneno - um verdadeiro phármakon -, reclamam a reinvenção do campo dos estudos literários e culturais no mundo acadêmico e nas práticas sociais.

\section{A}

${ }^{27}$ Leia-se, a propósito, a introdução do volume $\mathrm{O}$ arco e as pedras: fontes primárias, teoria e história da literatura, de Regina Zilberman et al., 2004, p.11-16. 


\section{REFERÊNCIAS}

Arquivo dos Acadêmicos: Guia geral. Coord. Sérgio Conde de Albite Silva. Rio de Janeiro: Academia Brasileira de Letras, 2003.

BARBOSA, Leila Maria F.; RODRIGUES, Marisa Timponi P. A trama poética de Murilo Mendes. Rio de Janeiro: Lacerda Editores, 2000.

BHABHA, Homi K. Disseminação: o tempo, a narrativa e as margens da nação moderna. In: ____. O local da cultura. Belo Horizonte: Editora UFMG, 1998. p. 198-238.

BORDINI, Maria da Glória. Acervos Sulinos: a fonte documental e o conhecimento literário. In: SOUZA, Eneida M. de; MIRANDA, Wander Melo (Org.). Arquivos literários. São Paulo: Ateliê Editorial, 2003. p.129-139.

BROCA, Brito. A vida literária no Brasil - 1900. 5. ed. Rio de Janeiro: José Olympio; Academia Brasileira de Letras, 2005.

CALDEIRA, João Ricardo de Castro. IEB: origens e significados - uma análise do Instituto de Estudos Brasileiros da Universidade de São Paulo. São Paulo: Imprensa Oficial SP; Oficina do Livro Rubens Borba de Moraes, 2002.

CANDIDO, Antonio. Formação da literatura brasileira (momentos decisivos). 3. ed. São Paulo: Martins, 1969. 2 v.

CARPEAUX, Otto Maria. História da literatura ocidental. 3. ed. Brasília: Senado Federal, 2008.

CARVAlHO, Abigail de O.; SOUZA, Eneida M. de; MIRANDA, Wander M. (Org.). Presença de Henriqueta. Rio de Janeiro: José Olympio, 1992.

CUNHA, Eneida Leal. A “Casa de Jorge Amado". In: SOUZA, Eneida M. de; MIRANDA, Wander Melo (Org.). Arquivos literários. São Paulo: Ateliê Editorial, 2003. p. 117-128.

FONSECA, Maria Odila. Arquivologia e ciência da informação. Rio de Janeiro: Editora FGV, 2005.

FOUCAULT, Michel. Em defesa da sociedade - curso no Collège de France (1975-1976). São Paulo: Martins Fontes, 1999.

MARQUES, Reinaldo. O arquivamento do escritor. In: SOUZA, Eneida M. de; MIRANDA, Wander Melo (Org.). Arquivos literários. São Paulo: Ateliê Editorial, 2003. p. 141-156.

MENESES, Ulpiano T. Bezerra de. A crise da memória, história e documento: reflexões para um tempo de transformações. In: SILVA, Zélia Lopes da (Org.). Arquivos, patrimônio e memória: trajetórias e perspectivas. São Paulo: Ed. Unesp; Fapesp, 1999. p. 11-29.

MIRANDA, Wander Melo. Nações literárias. Revista Brasileira de Literatura Comparada, São Paulo, Abralic, n. 2, p. 31-38, maio 1994.

RICCEUR, Paul. A memória, a história, o esquecimento. Campinas, SP: Editora da UNICAMP, 2007.

SOMMER, Doris. Ficções de fundação: os romances nacionais da América Latina. Belo Horizonte: Editora UFMG, 2004.

THAYER, Willy. A crise não moderna da universidade moderna. Belo Horizonte: Ed. UFMG, 2002. 
VASCONCELLOS, Eliane. Preservação da memória literária. In: SILVA, Zélia Lopes da (Org.). Arquivos, patrimônio e memória: trajetórias e perspectivas. São Paulo: Ed. Unesp; Fapesp, 1999.

ZILBERMAN, Regina et al. O arco e as pedras: fontes primárias, teoria e história da literatura. Belo Horizonte: Editora UFMG, 2004. 